\title{
Memoria, territorio y experiencia. Reflexiones a partir del pensamiento de W. Benjamin
}

\author{
Memory, territory, and experience. Reflections on the \\ thoughts of W. Benjamin
}

Memória, território e experiência. Reflexões a partir do pensamento de W. Benjamin

Matías Marchant*

\begin{abstract}
RESUMEN
La tesis que conduce este trabajo señala que la memoria puede ser considerada como un concepto que no refiere solo al tiempo. Ella puede ser situada en el territorio y en los objetos que llamamos "pertenencias". A partir de esta propuesta es posible comprender el componente ético que tienen los lugares o sitios de memoria. Dicho de otro modo, los recuerdos no solo tienen lugar en el tiempo, ellos son un pedazo de tierra y ello convierte al territorio en un espacio que requiere ser protegido por un mandato ético. A través del estudio de dos textos de Benjamin, Infancia en Berlín: hacia el mil novecientos y las Tesis sobre filosofía de la historia, se hace un recorrido que culmina sosteniendo que el trabajo de memoria es también una forma de establecer un vínculo ético y erótico con el otro.
\end{abstract}

\section{SUMMARY}

The thesis that leads this work points out that memory can be considered a concept that refers to time. It can be situated in the territory and in the objects that we call "belongings." From this proposal, it is possible to understand the ethical component that
Palabras clave: memoria, territorio, pertenencia, ética, recuerdo

Keywords: memory, territory, belonging, ethics, remembrance

* Chileno. Psicólogo, Universidad Diego Portales, Magister en Filosofía, Universidad de Chile. Candidato a Doctor en Filosofía, Universidad de Chile. Becario ANID. Contacto: matiasmarchant@uchile.cl

ORCID: https://orcid.org/0000-0001-9850-9988 
places or memory sites have. In other words, memories do not only take place in time but also a piece of land, which makes the territory a space that needs to be protected by an ethical mandate. Through the study of two of Benjamin's texts, Childhood in Berlin: Towards the Nineteen Hundred and Theses on the Philosophy of History, a journey begins. A road that culminates with the argument that memory is also a way of establishing an ethical and erotic link.

\section{RESUMO}

A teoria que conduz este trabalho indica que a memória pode ser considerada um conceito que não se refere apenas ao tempo. Ela pode estar situada no território e nos objetos que chamamos de "pertences". A partir desta proposta é possível compreender o componente ético de lugares ou locais de memória. Em outras

Palavras-chave: memória, território, pertences, ética, lembrança. palavras, as lembranças não acontecem apenas no tempo, elas são um pedaço de terra e isso converte o território em um espaço que precisa ser protegido por um mandato ético. Através do estudo de dois textos de Benjamin, Infância em Berlim por volta de 1900 e As teses sobre o conceito da história, é feita uma análise que culmina com o argumento de que o trabalho de memória é também uma forma de estabelecer um vínculo ético e erótico com o outro. 
"La lengua nos indica de manera inequívoca que la memoria no es un instrumento para conocer el pasado, sino sólo su medio. La memoria es el medio de lo vivido, al igual que la Tierra viene a ser el medio en que las viejas ciudades están sepultadas. Y quien quiera acercarse a lo que es su pasado sepultado tiene que comportarse como un hombre que excava. $Y$, sobre todo, no ha de tener reparo en volver una y otra vez al mismo asunto, en irlo revolviendo y esparciendo tal como se revuelve y esparce la tierra. Los «contenidos» no son sino esas capas que sólo después de una investigación cuidadosa entregan todo aquello por lo que vale la pena excavar: imágenes que, separadas de su conocimiento posterior, como quebrados torsos en la galería del coleccionista. Sin duda vale muchísimo la pena ir siguiendo un plan al excavar. Pero igualmente es imprescindible dar la palada a tientas hacia el oscuro reino de la Tierra, de modo que se pierde lo mejor aquel que sólo hace el inventario fiel de los hallazgos y no puede indicar en el suelo actual los lugares en donde se guarda lo antiguo. Por ello los recuerdos más veraces no tienen por qué ser informativos, sino que nos tienen que indicar el lugar en el cual los adquirió el investigador. Por tanto, stricto sensu, de manera épica y rapsódica, el recuerdo real debe suministrar al mismo tiempo una imagen de ese que recuerda, como un buen informe arqueológico no indica tan sólo aquellas capas de las que proceden los objetos hallados, sino, sobre todo, aquellas capas que antes fue preciso atravesar"

(BENJAMIN 2010 A, P. 350).

\section{1. ¿Quién escribe en Infancia en Berlín?}

El texto póstumo de Walter Benjamin Infancia en Berlín: hacia el mil novecientos, (Benjamin 1950), organizado por Theodor Adorno, fue escrito a partir de 1930, es decir, en torno a los 40 años del filósofo, y trabajó en él los últimos 15 años de su vida. Entregó varias partes de esta publicación a revistas, de manera separada y bajo pseudónimos, como un modo de apoyar su subsistencia económica (Adorno 1995). Este texto, junto a las tesis sobre filosofía de la historia será tomado como base para hacer un trabajo referido a los problemas y las preguntas que nos platea el tema de la memoria — ¿cómo se recuerda? ¿Qué se recuerda?-, teniendo en el horizonte las dimensiones políticas, eróticas y éticas de la memoria.

Para dar inicio a estas temáticas, nos plantearemos una pregunta de acceso y que es muy simple de formular: ¿quién escribe Infancia en Berlín hacia el mil novecientos ${ }^{1}$ ?

1 En lo sucesivo utilizaré la edición en castellano de editorial Abada, traducción de Jorge Navarro Pérez (Benjamin, Infancia en Berlín, 2015). 
No escribe el niño pues, si escribiera de este modo, las imágenes y las palabras estarían simplificadas, de la manera en que suele el adulto representar el lenguaje y el pensamiento de la infancia. Se trataría, entendido así, desde el sentido común, de una versión simple del pensamiento, con un vocabulario redundante y limitado. El caso extremo lo tenemos, por ejemplo, en la literatura para niños en que se reproduce la voz de un niño limitado en inteligencia, lenguaje y vocabulario; simplificado en pensamientos y emociones, poniendo en acto la caricatura de lo primitivo, confundiendo - en términos psicoanalíticosfantasía con pensamiento mágico. En el libro de Benjamin no se trata de una escritura de tiempo presente, de un niño que es espectador de lo que pasa aquí y ahora; es, en cambio, un ejercicio de memoria particular: "Yo... me acuerdo bien del deseo que se me cumplió" (Benjamin 201279 ). No es literatura infantil que sea dirigida a niños. Es otra cosa, es más bien una escritura que desde un presente se recuerda un pasado, a modo de fragmentos.

No escribe un adulto imaginando que alguna vez fue niño y que narra en su lugar. No hay una representación de la infancia de un modo idealizado, ya sea en el sentido de una ingenuidad o inocencia. Tampoco en el sentido descarnado y crudo, como lo sería en la obra de Dickens. No hay un trabajo de empatía ${ }^{2}$, a tal punto que permitiría reproducir con exactitud lo que vivió un niño, bajo la mirada de la complejidad y lo abigarrado de los sentimientos que ahí se suceden. No hay una búsqueda de una infancia perdida o irrecuperable, pues no hay un claro sentimiento de nostalgia o necesidad de volver a un momento dado. No se trata de memorias de tiempos mejores ni peores, son fotografías que pueden retratar distintos estados anímicos: sorpresa, curiosidad, decepción, alegrías, duelos, etc. Benjamin no escribe las memorias como una exploración de sí mismo. Tampoco se quiere mostrar la victoria del mundo adulto respecto del infantil, el abandono de una edad para encontrar otra mejor.

No escribe un adulto que recuerda lo vivido en la infancia de acuerdo con un proyecto autobiográfico. No es un ejercicio de memoria, tal como lo podríamos encontrar en el trabajo de San Agustín, Rousseau, Simone de Beauvoir, entre otros. No es un esfuerzo por encontrar el

2 Ni con el vencido ni con el vencedor. 
primer recuerdo de infancia, no es rescatar desde algún lugar recóndito las primeras experiencias de vida, aunque sea un fragmento de lo recordado personalmente o bien la búsqueda de la primera experiencia de infancia. Quiero decir, más precisamente, que no es un trabajo autobiográfico que siga algún tipo de cronología o una secuencia en la que los acontecimientos estén organizados temporalmente. No hay una sucesión en la que un hecho permita comprender el que seguirá. En este sentido no es un recuerdo organizado en torno al tiempo. Esta es la distinción central respecto de los otros recuerdos que se evocan aquí. No se utilizan los recuerdos para anticipar el presente. No hay una búsqueda de encontrar en el pasado las conexiones causales que podrían explicar el enigma presente. Hay, en un sentido muy diverso, lo que podríamos llamar aquí una "territorialización" del pasado, es decir se sitúa al pasado no en el tiempo, sino en un espacio concreto o material: en las calles de Berlín y en algunos trayectos.

Entonces, ¿quién escribe este texto que no es ni una autobiografía, ni un diario, ni tampoco, en sentido estricto, un proyecto de memorias? Situemos un poco mejor la pregunta. Infancia en Berlín reúne una serie de fragmentos, opúsculos, que dan cuenta de distintos temas o contenidos, como por ejemplo lugares de Berlín, el parque, el mercado, el cine, las conmemoraciones nacionales, el teléfono, juegos, vacaciones, el colegio, mañanas de invierno, entre otras. Tienen un lugar destacado en estos fragmentos los objetos de la infancia: pupitres, armarios, carruseles, libros, juguetes, las cuerdas de tender la ropa, etc. Lo que anuda los distintos textos son los recuerdos personales de un periodo particular que situamos en la infancia, si por ella entendemos un periodo suficientemente amplio que comprende los primeros recuerdos, junto con aquellos que le ponen término y que asociamos habitualmente a la juventud o adolescencia, y que en el texto de Benjamin se asocian al descubrimiento del sexo; los libros e imágenes del cine prohibidos por la edad, por el solo hecho de ser niño, ponen un manto y una cubierta respecto de las manifestaciones de la sexualidad adulta. Aunque bien es sabido que la sexualidad adulta es tan solo la realización — la puesta al descubierto- de los deseos y anhelos infantiles incumplidos ${ }^{3}$.

3 "Parece una paradoja - dice el psicoanálisis-, pero en cierta forma, el cumplimiento de muchos deseos infantiles sólo es posible cuando el individuo ha crecido" (Klein y Rivière 1990 82). 
La escritura de Benjamin tiene relación con lo que Adorno identifica como "arquetipos históricos", marcados por "la sombra del Reich hitleriano". Imágenes que "abrazan ensoñadoras el escalofrío de lo largamente ido", en las que “...el ingenio burgués se ve a sí mismo en el aura ruinosa del propio pasado biográfico: como reflejo" (Adorno 1995 73). Se trata de "fotografías de cuento", "ruinas" de la infancia, de "la vida largamente perdida" (Ibíd.). Efectivamente, uno podría tratar cada uno de los fragmentos como fotografías sacadas en distintos momentos de la infancia de Benjamin, a lo más como pequeños cortometrajes, que no tienen otro propósito que retratar un periodo breve pero significativo $^{4}$ de tiempo. Es como si un fotógrafo pudiera viajar nuevamente a su infancia y captar las imágenes que retrospectivamente encontraron un nuevo sentido para el devenido adulto, pero en esta toma de registro no se obtiene necesariamente una instantánea de los contenidos más relevantes, sino del medio en que los recuerdos tuvieron lugar. Es decir, no es un niño que saca fotografías de su presente, es un adulto que toma imágenes de la infancia, ahora que el pensamiento adulto ha dominado ya por completo la infancia y busca en ella las experiencias que parecen desgarradas de la memoria. Lo más sobresaliente de este método es que la instantánea que nos ofrece Benjamin es pocas veces el contenido central. Se esbozan, claro, el amor, el sexo, la muerte, la mentira y la angustia, pero en vez de tratar de ellos directamente nos muestra el terreno (el sitio o el lugar) en que ellos se encontraban.

Infancia en Berlín da lugar a un contenido temporal de la memoria. Aquí no hay un intento de vincular la relación de la memoria con el pasado y con un tipo de verdad. Trabajar con la memoria nos conduce frecuentemente a pensar la manera en que ésta se relaciona con un tiempo anterior (y todos los límites que tiene la recuperación del pasado) y si ella puede ser fidedigna. Nos preguntamos sobre el contrato que establece la memoria con la verdad relativo a lo ocurrido, en el que aparece con cierta frecuencia la desconfianza de su total transparencia respecto del pasado. Se asocia a una experiencia subjetiva que

4 Aun cuando la significación de ningún modo es evidente a primera vista, no es un trabajo ya dado. No hay una diferenciación entre las historias que se narran, entre las pequeñas y las grandes, simplemente se relatan como un cronista de la historia. "El cronista que detalla los acontecimientos sin discernir entre grandes y pequeños, tiene en cuenta una verdad de que nada de lo que alguna vez aconteció puede darse por perdido en la historia" (Benjamin 2009 40). 
da cuenta de una mirada muy particular sobre algo ya ocurrido. Con el concepto de "memoria", en este enfoque, renunciamos a pensarla como una cristalización de una verdad para transformarla en un punto de vista. Finalmente, nada de esto está en cuestión en el escrito de Benjamin y su originalidad está en que, a partir de la interpretación que queremos dar aquí, se puede hacer una relación entre la memoria y los objetos.

En el recuerdo no solo importa lo sucedido. Un recuerdo no basta si éste solo evoca el contenido de lo ocurrido. Un recuerdo es "lisiado" si éste solo evoca el hecho desnudo sin dar cuenta dónde fue hallado, si este es solo una fotografía que sitúa una sola imagen o figura (en vez del fondo) y omite el marco en el que ella se encuentra ${ }^{5}$. Los recuerdos sin contexto - como lo son las ideas platónicas- han reforzado la representación de la memoria como objetos sin historia y por sobre todo sin territorio. En el afán de conquistar la universalidad del conocimiento humano, el contexto haría obstáculo para su descubrimiento. Los laboratorios de los científicos fueron y siguen siendo, a menudo, espacios sin historia, solo así - se nos prometía (por ejemplo, en clases de ciencias positivas) - encontraríamos los conocimientos seguros. Para que la experiencia se volviera fuente de conocimiento ella debería producirse de igual manera en un extremo y en otro extremo del planeta $^{6}$. Como si los laboratorios pudieran controlar su historia (sus orígenes, antecedentes, luchas y las fuerzas dinámicas que le dieron lugar) para permitir el conocimiento ajeno a toda consideración histórica. Los fenómenos naturales han de ocurrir de la misma manera desde la creación del mundo hasta el tiempo presente. Como por ejemplo la fuerza de gravedad de la Tierra ha de ser siempre la misma, independientemente del lugar o momento en que ella se pone a prueba.

Para la experiencia humana, la más concreta, la más próxima, no solo importa qué ocurrió, es tanto o más importante saber dónde sucedió, del mismo modo a cómo se sucedieron los hechos. No basta con relatar un recuerdo, es absolutamente necesario tener referencia exacta de dónde ocurrió lo relatado. En el relato de un crimen no bas-

5 La foto en su contexto.

6 Esto era una forma de suprimir la experiencia, tal como Agamben la trabaja y señala en su libro Infancia e historia (Agamben 2001). 
ta con decir, sin duda, "ha muerto fulano". Un recuerdo sin una calle que lo aloje es una memoria coja de lo ocurrido. Un recuerdo sin un espacio definido pone en duda al hecho mismo. Los sueños tienen la cualidad de no tener un territorio definido, ellos pueden producirse en espacios que no se corresponden con los existentes; pero la memoria, si ella se realiza de manera cabal, requiere del territorio ${ }^{7}$. Benjamin recuerda haber conocido la experiencia del amor en un lugar preciso, en el parque Tiergarten, y más importante que el contenido fue el espacio: "pues ahí mismo o muy cerca habitaba esa Ariadna en cuya cercanía vine a comprender por vez primera eso (y no lo olvidé nunca) cuya palabra solo conocí más tarde, es decir, el amor" (Benjamin 2015 5-6). Los recuerdos, son fragmentos situados del pasado. Ocurren en un lugar específico. No se producen en cualquier parte, los recuerdos exigen su territorio. La experiencia requiere de una Tierra. La infancia tiene un lugar preciso y sus rincones privilegiados: "Así, una vez más, como en mi infancia, la Hidra de Lerna y el León de nemeo, alrededor de la Gran Estrella, tenía lugar, en la espesura" (Id. 8, énfasis mío). El recuerdo tiene su propio hilo de Ariadna, ovillo invisible que nos permite ingresar en los laberintos del pasado y que nos permite volver al presente gracias a ese cordel que dibuja un mapa del territorio en el cual uno podría perderse, como ocurría a los atenienses en el laberinto de Creta. El hilo es una forma de figurar el espacio, no el tiempo. Ese hilo es parte de la memoria; de este modo podemos decir que la memoria no solo es el material del hilo, es también su trazado. El trazado, a su vez, es la sucesión de los hechos, tan importante como el hecho mismo.

El recuerdo, al tener un lugar, permite volver a él en caso de que el que relata haya dejado alguna sombra de dudas. En ocasiones se puede perder el contenido del recuerdo y para recuperar lo perdido es necesario volver al lugar en el que se quedó lo extraviado. No obstante, lo olvidado no está ahí, solo que se perdió en ese lugar. Y en ese lugar está la pista de lo reprimido o de lo traumático, de la violencia o de lo perdido. Tomemos el caso del perito en investigaciones, lo que importa no es solo el crimen, es, además, el lugar del crimen y parte del proce-

$7 \quad$ En tal sentido, sueño y memoria tienen en común que ambos contienen un recuerdo, se diferencian, no obstante, en el hecho que uno no tiene un territorio (o su mundo es tan solo el espacio onírico) y en el otro su espacio debe hacer referencia a un territorio que suponemos real. 
dimiento, que tiene un lugar destacado, es la reconstrucción del crimen en la que el acusado debe participar para volver a realizar el acto, pero ahora de manera simulada, de manera tal de hacer una nueva historia que pueda calzar con la historia supuestamente recordada. Es tan importante este procedimiento que los acusados suelen salir de la prisión para participar de esta reconstrucción, término honesto decimos aquí, pues no se le llama memoria, simplemente una "nueva producción del crimen".

Benjamin va más lejos. El territorio de la memoria no solo contornea el contenido de la experiencia pasada, sino que también da un carácter propio a quien posee los recuerdos. El paisaje de la memoria no solo delinea lo ocurrido, también le da una forma, un carácter propio de quien rememora: "Como a partir de la casa y el barrio en que vive una persona podemos conformarnos una idea de cómo sea su naturaleza" (Id. 32). El terreno en el que están los recuerdos delinea su carácter y nos advierte de sus particularidades.

El padre de Benjamin, nos relata el filósofo, le mintió al narrarle la muerte de su primo, quien habría fallecido de un infarto cardiaco; no obstante fue de sífilis. Para Benjamin esta primera mentira tuvo un efecto en relación con el lugar: "Le pregunté qué era un infarto y me lo contó prolijamente. No comprendí mucho. Pero, esa noche, mi cuarto y mi cama se grabaron para siempre en mi memoria como te fijas en algún lugar al que algún día tienes que volver para recoger algo olvidado" (Id. 27). Entonces, podemos decir, el recuerdo debe reproducir el medio o el terreno de todos los acontecimientos que se narran.

Infancia en Berlín hace el trabajo comprometido por Benjamin en Excavar y recordar, es decir, como un arqueólogo nos da cuenta del terreno en el que están alojados o sepultados los contenidos de la memoria, y, según el trayecto planteado por el filósofo, este nos da cuenta del medio o de las capas en la que se encuentran los objetos hallados (Benjamin, 2010a). La memoria es un territorio que ha de ser descrito. No es en absoluto indiferente el lugar en que todo ocurrió, pues ese terreno puede dar cuenta, de una manera incluso más fiel que el propio relato, de lo sucedido. Los objetos de la memoria tienen un lugar, y esos lugares son tan relevantes como la fecha del calendario en que se producen o pueden ser situados. Muchas veces el lugar reemplaza, incluso, el contenido de lo ocurrido, y los memoriales exigen que ellos 
se erijan y se conmemoren no solo en el día que se quiere recordar sino en el lugar en donde quiere ser rememorado. Los recuerdos no solo marcan una fecha en el calendario solar, marcan un pedazo de tierra y lo vuelven un terreno o espacio de protección sagrados. Espacios de memoria refuerzan la idea de que el recuerdo no solo tiene un eje temporal, y que recordar es volver ahí, en donde se produjo el hecho no tramitado, o la violencia o la separación o el daño irrecuperable. El duelo como manifestación de dolor requiere no solo de un lapso, requiere de un espacio o territorio en el que se pueda velar la ausencia. Así, podemos decir, la muerte reclama un lugar y un territorio al oponerse al olvido. Los cementerios necesitan límites pues, de otra manera, la memoria de los muertos no permitiría vivir el presente o ellos invadirían el hoy.

Memoria y territorio se necesitan uno al otro. La memoria está anclada a un lugar. Para afirmar esto podremos tener presente las tesis de Pierre Nora, quien nos señala que nuestro interés por los lugares de la memoria está ligado a un momento en que se toma conciencia de la ruptura con el pasado, y en ese desgarramiento respecto del pasado se despierta una memoria situada. "El sentimiento de continuidad se vuelve residual a los lugares. Hay lugares de memoria porque no hay más medios de memoria" (Nora 1984 XVII). Precisamente por esta posibilidad de olvido es que los hechos deben ser recordados no solo en el tiempo sino en lugares precisos. Nora afirma: "si habitáramos nuestra memoria no tendríamos necesidad de consagrarle lugares" (Id. XVIII).

\section{La memoria pertenece a los objetos y al territorio}

De este modo, si volvemos a la pregunta original ¿quién escribe Infancia en Berlín? Habremos de decir que, en buena medida, son las calles, los objetos, el territorio y el escenario que nos hablan. Benjamin escribe sus textos, pero bajo pseudónimo, es decir, su nombre propio no ocupa un lugar privilegiado, no son las memorias de Benjamin, son las memorias de un autor desconocido, son recuerdos - dicho en términos de Pierre Nora- desgarrados. "Esa dignidad (...) solo se acompaña, para nosotros, de la comprobación de una marginación evidente [de Benjamin], que iba a culminar en una pérdida de crédito de su firma en el mundo editorial" (Monnoyer 2012 50). Son las calles, los objetos y las fotografías del recuerdo que serán relevadas, y el sujeto 
del recuerdo podrá ser sustituido o quizás mutilado. Son los espacios de memoria los que hablan más allá del sujeto que los enuncia. Entendiendo aquí que los objetos son situados y, por lo tanto, en este trabajo se entienden dentro de la lógica del territorio que hemos explicitado más arriba. Hay una exaltación de las cosas, y en particular del nombre de las cosas en el ejercicio de memoria de Benjamin, y este será el recorrido que nos ofrecerá como trabajo: una nueva vía de reflexión respecto nuestra relación con la memoria. Ella debe ser situada y deben ser las cosas (las calles, las escenas, las pequeñas historias) las que deben hablar, porque ellas son parte del territorio. "La esencia lingüística de las cosas es su lengua (...) la esencia lingüística del hombre es su lengua (...) la lengua de los hombres habla en palabras" (Benjamin 2010b 130). Benjamin deja trozos de sí en cada calle, en cada lugar.

Decimos entonces que quien escribe Infancia en Berlín no es Benjamin. Primero, en el sentido literal del término, dado que no es su nombre quien encabeza (sobre todo en las publicaciones anónimas) el recuerdo. Podemos afirmar que escriben los objetos, que escriben los espacios, en el sentido polifónico del término, que escribe el territorio en donde la experiencia tuvo lugar. ¿Pueden escribir los objetos, pueden las cosas tener la memoria de la experiencia humana? Sin duda es absurdo plantear que son las cosas las que escriben los acontecimientos, pero no es equivocado decir que, en la experiencia humana, nos comportamos como si los lugares tuvieran nuestra memoria y a ello le llamamos "pertenencia". Es muy frecuente que un lugar, un olor, una configuración de luz y calor gatillen el recuerdo. No obstante, para quien recuerda, son las cosas las portadoras de memoria y no el sujeto que la produce. $\mathrm{O}$ bien, si se quiere llegar a un término medio, es la interacción de ambas condiciones las que produce el recuerdo. Pero en Benjamin no será contradictorio señalar que las cosas, los objetos y los territorios comunican el recuerdo. La memoria de las cosas no corresponde a un pensamiento mágico y animista; según el filósofo, corresponde a una característica que es propia de la lengua.

Benjamin nos pregunta directamente:

La esencia lingüística del hombre es por lo tanto nombrar las cosas. ¿Por qué las nombra? ¿Con quién se comunica el hombre? - ¿Es acaso este problema en el caso del hombre distinto que en otras comunicaciones (lenguas)? ¿Con quién se comunica la lámpara? 
¿Y la montaña? ¿Y el zorro? - Pero aquí la respuesta dice: con el hombre. Ello no es en absoluto antropomorfismo (...) si la lámpara y la montaña y el zorro no se comunicaran con el hombre ¿cómo podría nombrarlos? (Id. 131).

De modo que lo anterior nos permite afirmar que la disponibilidad para la memoria está anclada y pervive en los objetos y los territorios. Si los objetos pueden comunicar, entonces no cabe duda de que el contenido de ella no puede ser otra cosa que los recuerdos que ellos portan. Es tan evidente que los objetos recuerdan que cuando el duelo no ha podido ser realizado, en el caso dramático y extremo por ejemplo de la muerte de un hijo, todos los objetos del hijo, su pieza normalmente (su espacio y sus objetos), permanecen por mucho tiempo y los deudos no pueden deshacerse de ellos, del mismo modo que quien quiere deshacerse de los malos recuerdos comienza primero por un cambio y restructuración de todos los objetos y espacios que ya no se quieren recordar, que se quieren dejar atrás. La memoria tiene una relación privilegiada con los objetos, y podemos decir que hay territorios de memoria y ello produce orgullo (o vergüenza) en quienes reciben y deben transitar por ese camino de memoria ${ }^{8}$.

Escribe Berlín en Infancia en Berlín, escriben sus lugares, sus parques, sus barrios y la casa en la que el niño vivió en Berlín.

Cuando nos enamoramos, no solo lo hacemos de la persona amada, lo hacemos también de sus recuerdos, de sus calles, de los aromas y los espacios que ha habitado. La relación no solo está situada en la persona amada sino también por los recuerdos que ella trae. En el caso de que la persona fuera extranjera, entonces esta relación con los objetos de la memoria se torna aún más evidente, puesto que lo que se

8 Escribe una madre en duelo por su hijo ya muerto llamado Cris. "Nunca quise cerrar el dormitorio del Cris, estaba siempre abierto (...) Dejé las cosas de mi hijo tal cual, hasta que pude entrar pasados los cuatro meses, y hacer un orden y limpieza antes de salir de vacaciones. Estoy con una pena infinita. Hoy limpié tu mesón de la tele, cada cosa, cada cosita, cada detalle (...) ¡Qué dolor!, tus cuadernos, tu letra, tus anotaciones. ¿Cómo mirar todo esto sin destrozarse, tanta belleza que no está, dónde estás? ¿Me escuchas? (Vera 2003). Este relato es, precisamente, la prueba viva y trágica, al mismo tiempo, de que, frente a este sentimiento desgarrador, los lugares tienen un papel fundamental en el mantenimiento del recuerdo. $O$ inclusive más, que el lugar puede ser consagrado precisamente por la falta de sentimiento de continuidad que la memoria no puede aportar por sí sola, como solo acto psíquico. Se requiere de un territorio real y concreto en el que ubicar la memoria: la memoria exige tener lugar. 
pone en juego en esa relación amorosa es, precisamente, encontrar los objetos del recuerdo, las calles de la infancia, la música y los sabores que acompañaron al otro. Cuando se trata de otra lengua, entonces queda con más evidencia marcado que ella es un objeto de la memoria en tanto soporte sonoro, en tanto cobijo de infancia, en tanto memoria fundamental para hacer frente al cuidado de otro. Amar a otro es buscar los objetos de su memoria e intentar encontrarlos, muchas veces volver a reconstruirlos y la mayor parte de las veces transitar o visitar y pasar un tiempo en ellos ${ }^{9}$. Cuando odiamos sucede algo similar, no solo se aleja a la persona sino también hay una distancia con todos los objetos y espacios odiados, es necesario destruir, tirar y quemar las cosas, intentando con ello borrarlos de la memoria. Hay una memoria de los objetos y de los territorios que marcan las pertenencias y las identidades; lo decimos aquí, asumiendo que de la escritura y reflexión de Benjamin es posible sostener esta posición.

No se trata de una relación de contigüidad entre memoria y territorio, no se trata de una mera asociación de los recuerdos pues, de otro modo, los objetos y los espacios no tendrían la dignidad que tienen según el acontecimiento rememorado. Los espacios de memoria tienen su propia ética y, por lo mismo, no pueden ser sustituidos por un solo decreto o por la fuerza de una nueva asociación. Los monumentos expropiados por las potencias invasoras se constituyen hoy en día en la vergüenza de los museos y de los habitantes de las ciudades usurpadoras. Dice Benjamin: "no existe un documento de la cultura que no lo sea a la vez de la barbarie" (Benjamin 2009 43). El cuerpo también puede ser pensado como un territorio, es decir, se puede pensar como lugar de memoria, y su mutilación equivale a la pérdida de la memoria del mismo modo como el arrasar un espacio de memoria es un desgarramiento. Al vincular la memoria con una erótica podremos decir que dejar de amar es olvidar y el duelo es un amor sin cuerpo que está en búsqueda de un territorio para recordar ${ }^{10}$.

9 Esta es una tarea casi imposible para quien no pueda soportar los amores de antaño, en la medida que el presente de cada cual está marcado e influenciado por las relaciones pasadas que deben ser integradas a las relaciones amorosa presentes.

10 Una madre respecto a su hijo muerto lo escribe así: “Amputación. Eso es lo que sentimos todos los padres y madres que hemos perdido hijos, todos lo hemos sentido como la amputación de un miembro del propio cuerpo, cojo, manco, hasta que logramos 
El hombre dota al universo de vida. Los objetos se vuelven perecederos cuando son tocados por los hombres, los objetos y la naturaleza se vuelven finitos cuando el hombre entra en relación con ellos. Los objetos se resisten a sucumbir del olvido de los hombres; el desván con todos los objetos del pasado lucha aún por tener un lugar en el recuerdo. El relato de Benjamin hace énfasis en los objetos del recuerdo y los espacios. Decimos aquí que la ciudad tiene su propia memoria, imprime en cada cual su carácter y configura así una cierta relación con el mundo. No cabe duda de que todo territorio tiene su propia forma de recordar y recubre a sus habitantes de manera tal que puede inclinar sus preferencias, actitudes y ocupaciones. Los caminos transitados conservan la huella del caminar de los otros y, a cada paso, sabemos que ese sendero se vuelve terreno de inscripción de lo sido.

Arendt expresa así esta relación entre memoria y las cosas:

Todas las cosas que deben su existencia a los hombres, como los trabajos, las proezas y las palabras, son perecederas, están infectadas, por decirlo así, por el carácter mortal de sus autores. Sin embargo, si los mortales consiguen dotar a sus trabajos, proezas y palabras de cierto grado de permanencia y de tener su carácter perecedero, estas cosas, al menos en cierta medida, integran el mundo de lo perdurable y dentro de él ocupan un puesto propio, y los mortales mismos encontrarían su puesto en el cosmos, donde todo es inmortal a excepción del hombre. La capacidad humana que permite lograr esto es la memoria (Arendt 2016 71).

La memoria dona a las cosas una nueva propiedad, un cierto grado de permanencia, se vuelven, de cierto modo - las cosas del mundo o los territorios como queremos sostener aquí-, inmortales, integran el mundo de lo perdurable, frente a la amenaza de la discontinuidad de lo sucedido. Los territorios adquieren una fuerza y una propiedad, incluso independientemente de quien les otorgó esta nueva cualidad; tienen, desde ahora, una dignidad y posiblemente una ética propia.

reconstruirnos y reconstruir a nuestro hijo/a" (Vera 2003 112). Donde la pérdida de una parte del cuerpo equivale a arrasar con los sitios de memoria que mencionamos. 
Si la memoria es un territorio, entonces el encadenamiento entre hechos se parece mucho más a un camino, a un trayecto, o bien al hilo de Ariadna que traza una figura en una superficie. La sucesión de los hechos de la memoria ya no está organizada por el tiempo exclusivamente, está organizado más bien por el camino, por la serie de pasos que se dieron a modo de saltos, sin seguir necesariamente una secuencia temporal ni fija. Cronos no es el único que participa en la construcción del recuerdo, debido a que la memoria no se organiza exclusivamente según el orden del tiempo, sino en virtud de que cada paso supone un desplazamiento en el territorio. No es el tiempo lineal el que organiza los hechos o los acontecimientos, sino más bien su relación en el espacio en el que un paso se ubica respecto de otro.

El tiempo se escurre y posiblemente nadie puede sentirse dueño de él; mientras que con algunos objetos de la memoria puede haber una relación de pertenencia. Se puede identificar que existe en los objetos una cierta propiedad en la medida en que son objetos de memoria. Los objetos de la pertenencia pueden ser, a modo de ejemplo, las huellas de la relación con otro (Correa, Ford, Marchant y Sánchez 2016). La manera más sencilla de representarlo se encuentra en las fotos, instantáneas del tiempo, fijeza en el tiempo de algo que inscribe un hecho que se atesora como un objeto insustituible, que no puede ser intercambiado por otro y cuyo valor es exclusivamente personal. Las pertenencias (a diferencia de la propiedad o posesión) designan una cierta identidad y adquieren valor solo por el hecho de contener una memoria insustituible. Por ejemplo, en el caso de Benjamin sería el pupitre de la infancia. Esta materialidad de los objetos de la memoria se puede apreciar en la manera que tiene Benjamin de referirse a ellos: "Todas las propiedades de mi infancia iban creciendo así, y se disfrazaban en cajones, en cajas y anaqueles" (Benjamin 2015 74-75). En este caso, se trata de las pertenencias que además están dotadas, ahora, de una propiedad de lo vivo, como lo es el crecer. No es un animismo respecto de los objetos, es la forma en que la memoria se relaciona con ellos, su lugar en el tiempo. "El mueble parecía tener derechos tan consolidados a su lugar en el comedor como a su lugar en el tiempo, uno en el que daba testimonio de aquel parentesco que en un pasado oscuro unió al mobiliario y los inmuebles" (Id. 75, énfasis mío). 


\section{Infancia en Berlín y las Tesis sobre la filosofía de la historia}

El texto de Benjamin ampliamente conocido como las Tesis sobre la filosofía de la historia constituye un cuerpo de anotaciones que problematizan y encuentran diversos nudos críticos en el concepto de "historia". Cada tesis, cada apartado, contiene la posibilidad de numerosas posibilidades de interpretación. El texto tiene la estructura de un escrito abierto que deja enunciado tensiones y problemas; pero no solo eso, además plantea una serie de afirmaciones en las que se entrelazan relaciones que no son para nada evidentes, y que requieren de un intenso trabajo reflexivo para encontrar el hilo invisible que permite a Benjamin poner en cuestión una serie de concepciones tradicionales sobre la historia. Tanto más si se propone unir, por ejemplo, materialismo histórico y teología.

Sería inoficioso intentar dar cuenta de todas las posibles interpretaciones a las que ha dado lugar el texto de Benjamin, además que sería posible señalar que cada intérprete de la obra de Benjamin atrae para sí aquello que le permite, de cierto modo, apoyar sus propias tesis sobre el tema de la historia, el materialismo histórico y el lugar de la teología. Las tesis o los fragmentos de Benjamin permiten abordar tantos temas como los que aparecen esbozados y, dado que no se trata de una construcción definitiva, entonces es posible, a partir de todo aquello que queda abierto, proseguir líneas de reflexión personal y trabajar, desde lo esbozado en cada tesis, un conjunto de ideas que pueden luego ser desarrolladas.

En este contexto, me interesa relevar los aspectos que me parecen más centrales respecto del tema que he intentado elaborar o plantear en este trabajo, y que tienen relación con la reflexión de Benjamin respecto del pasado.

¿Infancia en Berlín es un trabajo que dialoga con las Tesis sobre la filosofía de la historia? ¿Son textos que tienen un vínculo entre sí o ellos se ocupan de temas del todo diversos y, por lo mismo, requerirían ser tratados en capítulos aparte si se quisiera abordar el pensamiento de Benjamin? Diremos que ambos son textos póstumos; por lo tanto, en cada uno de ellos su proyecto de publicación no encuentra en el autor su explicación y su relación respecto de un proyecto de obra o pieza 
dentro del puzle de temas que abordó. Ambos textos tienen un devenir propio y queda en manos de quienes finalmente publican sus textos la manera de situarlos respecto de lo que es posible llamar "el pensamiento de Benjamin". Se trata, sin duda, de textos de diversa índole. Tienen diversos objetos delante de sí. No obstante lo anterior, encontramos que en ambos el tema de la memoria tiene un lugar relevante y que puede ser objeto de una tematización o problematización. En ambos este asunto requiere ser trabajado con los escasos elementos que deben ser enriquecidos con nuevos lazos, conceptos y puntos de referencia.

Existe una relación entonces entre Infancia y las Tesis en la medida en que consideramos que Infancia en Berlín actualiza la "discontinuidad en la historia, a fin de validar la eficacia absolutamente singular del pasado como tal" (Oyarzún 1996 26). En Infancia en Berlín es evidente que se trata de relatos y fragmentos de un pasado pendiente, pedazos truncos, trozos o girones recortados. No hay ninguna idea de progreso en el texto, de sucesión de hechos que apunten a una conquista mayor de autonomía o autoridad sobre el recuerdo. Hay apuntes sobre hechos que dejan pendiente una exploración sobre la verdad, sobre el sexo, sobre el amor, la autoridad, etc. Ambos textos se abren a la muerte como condición de la experiencia, como condición de la escritura. Ambos textos son relatos íntimos, ocultos por un pseudónimo o bien en las anotaciones de una libreta aún en preparación.

Podemos entonces plantearnos la pregunta por la manera en que la noción de "experiencia" en Benjamin puede enriquecer la reflexión sobre la memoria. En las Tesis sobre la filosofía de la historia, según Oyarzún (1996), hay una forma en que la experiencia es tematizada y que rompe con los cánones más clásicos acerca de cómo ella ha sido tradicionalmente comprendida. Si la experiencia en el pensamiento tradicional aparece como algo que debe plantearse desde la singularidad, la inanticipalidad, la testimonialidad, con el trabajo de las tesis en Benjamin, la experiencia se abre de otra manera, permite una nueva forma de pensarla.

Para Oyarzún, el cambio de paradigma en relación con la experiencia puede ser planteado del siguiente modo:

Se sigue de esto un cambio fundamental en los índices de la experiencia que creímos oportuno colegir del análisis tradicional [de la 
experiencia]: la singularidad se vuelve, por así decir, macroscópica, lo inanticipable escapa a todo aquietamiento que pudiese aportar la virtud de lo analógico, el testimonio declarar la ausencia de testigo en el momento fugaz de la prueba (Oyarzún 1996 15).

En Infancia en Berlín encontramos un conjunto de pasajes en el que cada uno abre una serie de interrogantes que pueden situarse en torno a algunos temas. Ahora bien, si nos preguntáramos sobre la manera en que la experiencia da lugar a cada una de sus interrogantes, será posible volver a las Tesis sobre la filosofía de la historia bajo un nuevo lente o punto de vista. Por ejemplo, podríamos hacer una relación entre lo planteado en las Tesis III cuando señala: "El cronista, que detalla los acontecimientos sin discernir entre grandes y pequeños, tiene en cuenta la verdad de nada de lo que alguna vez aconteció puede darse por perdido para la historia" (Benjamin 2009 40). Podremos decir aquí que, en cuanto a los fragmentos de Infancia en Berlín, ellos son tan valiosos para el historiador como la narración de los momentos más importantes de la gran Historia de Berlín.

En la autobiografía se suele intentar cruzar la memoria con los acontecimientos de la historia, de ese modo se puede señalar una cierta pertenencia a una época dada, ya sea porque se ha tenido participación en las instituciones que cambiaron el rumbo de las cosas o porque se ha sido testigo de un acontecimiento señalado como un hito de una sociedad dada. Las memorias de Benjamin no aspiran a fijarse de modo inamovible a la historia, más bien ellas están al servicio de aquello que no ha entrado a la historia.

En la experiencia singular del autor de las memorias se suele hallar esa aspiración a que ellas encuentren lugar en la historia, como si la historia pudiese ser garantía de la veracidad del recuerdo ocurrido. A menudo la memoria es una manera de poner un punto de vista singular de lo que se llama "acontecimiento histórico". El historiador puede prescindir de cada memoria en particular y someterla a la razonable duda sobre la veracidad del recuerdo. Para eso se puede apoyar en los registros objetivos del periodo histórico que estudia. Los documentos consultados deben dar cuenta de una narración que se quiera única o suficientemente amplia como para hablar de los hechos del pasado como si fueran parte de una historia universal a la que le es necesario unir cada nuevo acontecimiento según la línea que se traza, habitual- 
mente - dice Benjamin - la del progreso. La historia que se narra es la historia de los vencedores, en cambio la de los vencidos - y particularmente su memoria- queda excluida de los grandes periodos de la historia. Benjamin lo dice así: "con quién empatiza el historiógrafo del historicismo. La respuesta, reza, inevitablemente: con el vencedor. Por los que dominan a la sazón son los herederos de todos lo que han vencido" (Id. 42).

La experiencia a la que hace referencia Infancia en Berlín tiene relación entonces con lo que es tematizado de otra manera en Tesis sobre filosofía de la historia. Se trata entonces de una experiencia que quiere revelar en cada pasaje aquello que pueda o no pertenecer a la historia. Es una experiencia, como señala Oyarzún, macroscópica y que puede verse reflejada en el hecho de que se trata de algo inédito, de algo que nos cambia. Se trata de una experiencia que da cuenta de que ella es tomada de improviso por una alteridad que se impone. "La historia, en todo lo que ella tiene, desde un comienzo, de intempestivo, doloroso, fallido, se acuña en un rostro, no, una calavera" (Benjamin, citado por Oyarzún, 1996 13). En Infancia en Berlín el autor da cuenta de aquellos acontecimientos que rompen con la relación tradicional con la verdad, como cuando su padre le miente respecto de la causa de muerte de su tío; rompen con la relación con la autoridad, como cuando se atreve a conversar con una prostituta; rompen la relación con Dios, como cuando se pregunta sobre el origen del sufrimiento.

La experiencia de Infancia en Berlín se caracteriza por no encontrar en ella ninguna posibilidad de construir una línea que dé cuenta de un estado del desarrollo, de paso hacia un estado superior. De hecho, se trata, a cada instante, de rupturas, pedazos rotos, pequeñas historias que dejan abierto un sinfín de interrogantes. Es una experiencia que no construye un recuerdo más sólido, sino que relampaguea y es una luz imprevista, y luego se apaga sin producir necesariamente ni una significación ni un sentido propiamente tal.

Es posible decir que, referido al tema de la testimonialidad, lo que brinda la posibilidad de decir "estuve ahí", tan propio o tan característico de la experiencia del testigo, no es el sujeto que la enuncia, sino los objetos de la infancia que actúan como testigos de lo acontecido. No es el sujeto, son esos objetos que reclaman el lugar de testigos ante los hechos relatados por Benjamin. Que los objetos sean testigos es lo que 
puede ayudar a sostener la lectura que quien recuerda, en el texto de Benjamin, lo hace a través de los objetos de memoria, que llamamos aquí "pertenencias", objetos del recuerdo que son testimonios de un vínculo que alguna vez se tuvo y que reclamaron para sí la posibilidad de brindar testimonio. Así, el testimonio pertenece también a los objetos que acompañaron mientras, por ejemplo, los amantes recordaron juntos.

\section{4. Ética y erótica de la memoria: dos insistencias de la memoria situada}

Dijimos en el texto que amar es el deseo de emprender una búsqueda por los objetos del otro. Los objetos no son tan solo los pensamientos o los sentimientos, son, dicho de un modo más fuerte aquí, los territorios del otro que han dejado en el cuerpo las marcas que permiten el recuerdo. Podemos explicitar aquí algunos supuestos que habían orientado la reflexión antes iniciada: Amar es disponerse a recorrer los territorios (las memorias) del otro. ¿Y cuál es el territorio que ha de recorrerse con el amado? No queda ninguna duda, y me apoyo en Benjamin para decir esto: es volver a hacer ese tránsito por la infancia supuesta del otro. Es asumir la infancia del otro como un territorio que se puede volver a recorrer junto a otro a modo de una ficción compartida. Infancia en Berlín en el caso de Benjamin, Infancia e historia en el caso Agamben, lector de Benjamin, son referencias a un cierto tipo de experiencia que ha de situarse en un lugar, ya no exclusivamente en el tiempo. Quizás podríamos decir aquí: hay un vuelco hacia esa relación con el lugar. El trabajo nos permite situar la memoria en un territorio. Este territorio es un lugar que tiene relación con los objetos. Pero los objetos de los que se trata no son nada más ni nada menos, en el caso de Benjamin, que los objetos de la infancia. ¿Y por qué la infancia? Apoyándonos en Agamben podemos decir que éste hace referencia a una experiencia particular o a una posición que situamos en la infancia. Lo situamos en la infancia porque refiere a una experiencia que, en términos de Agamben, está lejos de ser subjetiva, que se sitúa antes del lenguaje,

una experiencia "muda" en el sentido literal del término, una in-fancia del hombre, cuyo límite justamente el lenguaje debería señalar. Una teoría de la experiencia solamente podría ser en este sentido una teoría de la in-fancia, y su problema central debería formularse 
así: ¿existe algo que sea una in-fancia del hombre? ¿Cómo es posible la in-fancia en tanto que hecho humano? Y si es posible ¿Cuál es su lugar? (Agamben 2001 64).

He aquí el núcleo de la pregunta, pues por lo que interroga Agamben es precisamente por su lugar. La memoria tiene lugar y ese lugar puede ser, en otros términos, las marcas que porta el cuerpo, y ellas (primer lenguaje) son trazos ubicados en un espacio. Amar, decimos nuevamente, tiene relación con dejar inscrito en el cuerpo del otro las marcas de una huella común y que llamamos aquí "pertenencia". Construir un espacio en donde pueda tener lugar una memoria compartida, todo lo que resulta inapropiable de la relación con el otro. Amar es ofrecer la memoria de aquello que ni siquiera puede ser recordado, pero que implica habitar la relación con los objetos que Benjamin $-\mathrm{y}$ todo amante- dejó marcados por un vínculo común.

La reflexión ética de la memoria nos acude con una variable que solo podremos dejar esbozada aquí respecto de los lugares de memoria, de los museos de la memoria, de los territorios de la memoria. Pensar en la defensa de los lugares de la memoria, la protección del pupitre de Benjamin, la recuperación de espacios en los que se ejerció la violencia extrema o la tortura, el lugar en el que se cometieron asesinatos que simbolizaron el terror de Estado no es analizado aquí tan solo como el deber de recordar. El precepto o el mandato de recordar no bastan, no son suficientes, no tienen la fuerza para imponerse como una regla. Para recordar hace falta un lugar que permita poner en marcha un trabajo que contempla la dignidad de recordar. El cementerio, desde tiempos inmemoriales, recuerda el deber de memoria. Pero, decimos aquí, no basta con aplicar y someter a los otros al deber de recordar. El museo y el memorial muchas veces dejan de ser una experiencia, dado que, como bien plantea Benjamin, "la aplastante mayoría de la humanidad se niega a adquirir una experiencia: prefiere que la experiencia sea capturada por la máquina de fotos" (Id. 10). Ahora bien, para que los museos y territorios de la memoria sean eficaces, es decir, para que ellos puedan hacer el ejercicio de la memoria, tal como explícitamente su creador lo quiere hacer, es necesario conducir a la idea de que no existe un ejercicio de memoria si ella no refiere a la experiencia compartida con otro. Queremos decir aquí que, para que el ejercicio de memoria logre su cometido, es necesario re- 
cordar dentro de un territorio que dé lugar nuevamente al ejercicio de recordar junto con otro. Pensar el recuerdo como una pertenencia que se comparte a partir de la experiencia del otro. La fuerza impuesta al recuerdo, como suelen hacerlo los libros escolares de historia, no hace más que someter a las nuevas generaciones a una identidad forzada, pero nada asegura el éxito de la tarea de memoria. Se puede promover una adscripción ciega a un hecho que constituye un acontecimiento fundador de un ideal patrio, pero este recuerdo no conlleva en sí ningún valor ético; el recuerdo forzado produce el mismo efecto que la obligación de pensar. No se puede obligar a pensar, menos por sí mismo, eso es un contrasentido. Recordar, decimos aquí, y nuevamente pensamos que nos apoyamos en Benjamín, trata del ofrecimiento de un recuerdo que contenía un vínculo. Recordar a solas un homenaje, aunque grupal, pero que no acarrea ningún vínculo consigo, es tan solo la fuerza de la costumbre (es nemotécnica, no memoria), carece de valor ético, es obediencia, no es posibilidad de recordar libremente con otro. El ejercicio de la memoria, así expuesto, queda desprovisto de un carácter ético.

Asumimos aquí la interpretación de que el proyecto de Benjamin se relaciona con el hecho que el recuerdo tiene valor ético solo si es un recuerdo compartido, en el que el hecho de rememorar es un don que se comparte con otro. Es volver a contar la historia que narra una experiencia irrepetible para cada cual. El desgarramiento que nos anuncia la memoria y que protege con sus territorios tiene relación con otra pérdida, la pérdida de la posibilidad de recordar con otro. Insistimos aquí en que la memoria es un ejercicio de alteridad, aspecto que hemos querido mostrar a partir del desarrollo de los argumentos expuestos en este trabajo.

\section{Bibliografía}

Adorno, T. Sobre Walter Benjamin (Rolf Tiedemann ed.). (C. Fortea, Trad.) Barcelona: Cátedra, 1995.

Agamben, G. Infancia e historia. Buenos Aires: Adriana Hidalgo, 2001. Arendt, H. "El concepto de historia: antiguo y moderno", Entre el pasado y el futuro, H. Arendt. Buenos Aires: Ariel, 2016. 67-144.

Benjamin, W. "Sobre el concepto de historia", La dialectica del suspenso, W. Benjamin. Santiago, Chile: LOM, 2009. 
Benjamin, W. Excavar y recordar (vols. Libro IV, Vol 1). (J. N. Pérez, Trad.) Madrid: Abada, 2010a.

Benjamin, W. "Sobre el lenguaje en general y sobre el lenguaje de los hombres", Ensayos escogidos, W. Benjamin y H. Murena (Eds.). Buenos Aires: El cuenco de plata, 2010b. 127-147.

Benjamin, W. Escritos Franceses. (H. Pons, Trad.) Buenos Aires: Amorrortu, 2012.

Benjamin, W. Infancia en Berlín (Tillman Rexroth ed.). (J. N. Pérez, Trad.) Madrid: Abada, 2015.

Correa, M., Ford, A., Marchant, M. y Sánchez, L. «Posesiones y pertenencias: una distinción necesaria para el trabajo con niños y niñas privados de cuidado parental", De Familias y Terapias (2016): 75-87.

Klein, M. y Rivière, J. Amor, odio y reparación. Buenos Aires: Hormé, 1990.

Monnoyer, J.-M. "Introducción », Escritos Franceses, W. Benjamin. Buenos Aires: Amorrortu, 2012. 15-67.

Nora, P. Les lieux de Mémoire: 1 La République. Paris: Gallimard, 1984.

Oyarzún, P. "Cuatro señas sobre experiencia, historia y facticidad", $L a$ dialéctica en suspenso, W. Benjamin. Santiago, Chile: LOM, 1996. 7-38.

Vera, I. CRIS o la plenitud del vacío. Santiago, Chile: Cuarto Propio, 2003. 